\title{
Zr environment and nucleation role in aluminosilicate glasses
}

Laurent Cormier*, ${ }^{*}$, Olivier Dargaud ${ }^{2}$, Georges Calas ${ }^{1}$, Cécile Jousseaume ${ }^{3}$, Sophie Papin ${ }^{3}$, Nicolas Trcera ${ }^{4}$, Andrea Cognigni ${ }^{5}$

${ }^{1}$ Institut de Minéralogie, de Physique des Matériaux, et de Cosmochimie (IMPMC), Sorbonne Universités, UPMC Université Paris 06, CNRS UMR 7590, Muséum National d'Histoire Naturelle, IRD UMR 206, 4 place Jussieu, F-75005 Paris, France

${ }^{2}$ Cité de la céramique - Sèvres et Limoges, 2 place de la Manufacture, 92310 Sèvres, France

${ }^{3}$ Saint-Gobain Recherche, 39 Quai Lucien Lefranc, 93303 Aubervilliers, France

${ }^{4}$ Synchrotron SOLEIL, L'Orme des Merisiers, BP 48, St Aubin, 91192 Gif-sur-Yvette Cedex, France

${ }^{5}$ Elettra Sincrotrone Trieste S.C.p.A., Strada Statale 14, 34149 Basovizza, Trieste, Italy

\begin{abstract}
We have investigated the role of $\mathrm{ZrO}_{2}$ on the nucleation/crystallization properties of aluminosilicate glasses. A comparison between $\mathrm{Zr}$-free and $\mathrm{Zr}$-bearing glasses shows that adding $\mathrm{ZrO}_{2}$ favors nucleation in $\mathrm{Li}$-, $\mathrm{Mg}$-, $\mathrm{Ca}$ - and $\mathrm{Zn}$-bearing glasses and has no effects in Na-bearing glasses. The $\mathrm{Zr}$ environment has been elucidated coupling X-ray absorption spectroscopy at both $\mathrm{Zr} \mathrm{K}$ - and $\mathrm{L}_{2,3}$-edges. The $\mathrm{Zr}$ environment corresponds to six-fold coordinated sites ( $\mathrm{Li}$ and $\mathrm{Na}$ glasses) and seven-fold coordinated sites ( $\mathrm{Mg}, \mathrm{Ca}$ and $\mathrm{Zn}$ glasses), indicating the coordination number has little influence on the ability to crystallize. Direct $\mathrm{Zr}-\mathrm{Zr}$ polyhedral linkages are observed for all glasses except the Na-bearing one. Since no correlation between the local $\mathrm{Zr}$ site and its ability to promote nucleation can be observed, the origin of the nucleating role of $\mathrm{Zr}$ has been interpreted as resulting from the $\mathrm{Zr}$ distribution with the aluminosilicate matrix. The poor crystallization ability for Na-bearing glasses is due to the lack of direct $\mathrm{Zr}$-Zr linkages. Medium range ordering appears as a key parameter to explain properties of Zr-bearing glasses.
\end{abstract}

KEYWORDS: non-crystalline materials, oxides, differential scanning calorimetry (DSC); XAFS (EXAFS and XANES); nucleation; optical properties

\section{AUTHOR INFORMATION}

Corresponding Authors

* To whom correspondence should be addresses. E-mail: cormier@impmc.upmc.fr. 


\section{Introduction}

Glass-ceramics represent advanced glass-crystal composite materials with improved physical and chemical properties (e.g. low thermal expansion coefficients, high thermal and chemical stability, high mechanical strength), which leads to many innovative applications $[1,2]$. During heat treatment of a parent glass, nucleating agents, such as $\mathrm{TiO}_{2}$ and/or $\mathrm{ZrO}_{2}$, help to develop internal homogeneous nucleation, while decreasing the crystallization temperature, and to control the crystallization mechanism and the size distribution of the final crystals $[3,4]$.

Different explanations have been proposed about the structural origin of the role played by nucleating agents in glasses. Early works indicated the possibility of a liquid-liquid phase separation $[5,6]$, followed by the formation of crystalline phases containing theses nucleating elements. Recent experimental investigations have shown that the pristine glass, despite being macroscopically homogeneous, presents structural fluctuations at the atomic scale $[7,8]$. These inhomogeneities may prefigure the crystalline phases appearing upon heat treatment and lower the energy barrier for nucleation, explaining at least partially the discrepancies between experimental and theoretical nucleation rates $[9,10]$. These static density fluctuations may correspond to a non-homogeneous distribution of nucleating agents [11] or to preferential linkages between coordination polyhedra $[12,13]$.

The environment around most nucleating agents ( $\mathrm{Ti}, \mathrm{Zr}, \mathrm{Cr}$ ) can be selectively investigated by X-ray absorption spectroscopy (XAS), giving structural information on site geometry and the topology of the linkage of these sites to the glassy network [14-20]. In addition, much information on the local structure around $\mathrm{Zr}$ in glasses has been gained by coupling XAS data with numerical modeling [21]. The role of $\mathrm{Zr}$ is of special interest because this element is an active nucleating agent at low content in alkali or alkaline-earth aluminosilicate systems [4,19,22,23]. Conversely, $\mathrm{Zr}$ has been considered to stabilize nuclear waste glasses against alteration in closed systems [24-26]. In this case, $\mathrm{Zr}$ occurs in $\mathrm{ZrO}_{6}$ octahedra, which are charge-compensated by $\mathrm{Ca}^{2+}$ ions and share corner with silicate groups. Under silico near-saturation conditions, $\mathrm{Zr}$ maintains its coordination due to its ability to retain $\mathrm{Ca}^{2+}$ ions for charge-compensation, thus participating to the preservation of the silicate network connectivity.

Describing the atomic-scale processes of the early steps of nucleation/crystallization should allow a better understanding of the relation between physico-chemical properties of 
Zr-bearing glasses and the structure, including its chemical dependence. This knowledge is mandatory to predict the role of elements such as $\mathrm{Zr}$ in the modification of glass properties during crystallization. In this study, we demonstrate that drastic modifications of the $\mathrm{Zr}$ environment in aluminosilicate glasses occur by changing the nature of the alkali and alkaline earth, for a similar network-forming content. The comparison between Zr-free and Zr-bearing glasses illustrates the role of this element on the nucleation/crystallization properties for these glasses. Zirconium can be found in 6- or 7-fold coordinated sites in the investigated glasses, indicating that $\mathrm{Zr}$ coordination does not control nucleation. Medium range ordering, among which the linkage between the $\mathrm{Zr}$ sites, appears to be a key parameter in defining the properties of Zr-bearing glasses.

\section{Experimental}

\subsection{Materials}

The glasses (Table 1) were prepared from high-purity compounds. Starting materials were ground together, dried and melted in a Pt crucible at $1650^{\circ} \mathrm{C}$ for 2 hours, then quenched by immersing the bottom of the crucible into water. Resulting glasses were ground and molten once again to ensure a good homogeneity. X-ray powder diffraction patterns confirmed that all samples are amorphous.

$\mathrm{TiZrO}_{4}$ [27], natural elpidite, $\mathrm{Na}_{2} \mathrm{ZrSi}_{6} \mathrm{O}_{15} \cdot 3 \mathrm{H}_{2} \mathrm{O}$ [28], lemoynite, $(\mathrm{Na}, \mathrm{K})_{2} \mathrm{CaZr}_{2} \mathrm{Si}_{10} \mathrm{O}_{26} \cdot 5-6 \mathrm{H}_{2} \mathrm{O}$ [29] and synthetic baghdadite, $\mathrm{Ca}_{3} \mathrm{ZrSi}_{2} \mathrm{O}_{9}$ (synthesized following [30]) [31] were used as model compounds of 6-fold coordinated $\mathrm{Zr}$, ${ }^{[6]} \mathrm{Zr}$, with variable degrees of site distortion. Baddeleyite $\left(\mathrm{m}-\mathrm{ZrO}_{2}\right)$ [32] was used as model compound of 7-fold coordinated $\mathrm{Zr},{ }^{[7]} \mathrm{Zr}$. Cubic zironia $\left(\mathrm{c}-\mathrm{ZrO}_{2}\right)$ [33], tetragonal Y-doped zirconia (t$\mathrm{ZrO}_{2}$ from Saint-Gobain Zirpro) [33] and natural zircon $\left(\mathrm{ZrSiO}_{4}\right)$ [34] were used as model compounds of 8 -fold coordinated $\mathrm{Zr}$, ${ }^{[8]} \mathrm{Zr}$. $\mathrm{t}-\mathrm{ZrO}_{2}$ contains less than $3 \% \mathrm{~m}-\mathrm{ZrO}_{2}$. Each model compound was verified by X-ray powder diffraction.

\subsection{Differential Scanning Calorimetry}

Differential Scanning Calorimetry (DSC) thermograms were recorded on a Setaram Multi-HTC 96, under $\mathrm{N}_{2}$ flux, in Pt crucible with a heat rate of $5 \mathrm{~K} \mathrm{~min}^{-1}$ from $450^{\circ} \mathrm{C}$ up to $1550^{\circ} \mathrm{C}$. The samples were grounded and sieved at $45 \mu \mathrm{m}$ to control the granulometry. Energy 
calibration was made with respect to sapphire and calculations were carried out as explained previously [35].

\section{3. $\mathrm{Zr} L_{2,3}$-edges $X$-ray absorption spectroscopy}

$\operatorname{Zr} L_{2,3}$-edges XANES (X-ray Absorption Near Edge Structure) spectra have been collected on the LUCIA beamline of the SOLEIL synchrotron (France) using a Si(111) double crystal monochromator [36]. The XANES spectra have been recorded in the fluorescence mode with a silicon drift diode detector, and steps of $0.1 \mathrm{eV}$ over the $\mathrm{L}_{3}$ and $\mathrm{L}_{2}$ energy ranges (2200$2250 \mathrm{eV}$ and $2300-2315 \mathrm{eV}$, respectively), with a counting time of $3 \mathrm{~s}$. At least two spectra have been averaged to increase the signal to noise ratio. Bulk samples were fixed on a graphite tape stuck on copper slides. Spectra have been normalized to the high energy side of each edge [37].

\subsection{Zr K-edge X-ray absorption spectroscopy}

X-ray Absorption Spectroscopy (XAS) data were collected at Zr K-edge (17998 eV) on the XAFS beam line of the Elettra synchrotron (Italy) [38]. Data were recorded in transmission mode with a $\mathrm{Si}(111)$ monochromator and a $2 \mathrm{~s} /$ point integration time, on powdered samples mixed with the appropriate amount of boron nitride to match an absorption step of $\sim 1$. An average of 8 spectra was measured at $77 \mathrm{~K}$ in a liquid nitrogen cryostat. Incident and transmitted X-ray intensities were measured using Ar filled ionization chambers. The beam size was approximately $8 \mathrm{~mm}$ by $3 \mathrm{~mm}$. Energy was calibrated respective to metallic Zr.

\subsection{EXAFS data reduction and analysis}

EXAFS (Extended X-ray Absorption Fine Structure) data reduction and analysis were performed by means of the GNXAS software package [39]. This program analyzes the data directly in energy space by comparing the raw experimental data $\mu^{\exp }(\mathrm{E})$ with a model absorption coefficient $\mu^{\text {th }}(\mathrm{E})$. This model includes the structural signal, $\chi(E)$, and other components of the spectrum (edge-jump, post-edge atomic background). Moreover, the modulation of the atomic post-edge background can include the effects of multiple excitation 
edges that are present in the $\mathrm{Zr} \mathrm{K}$-edge absorption spectrum. The theoretical $\chi(\mathrm{E})$ is given by a combination of $n$-body signals, $\gamma^{(\mathrm{n})}$, calculated $a b$ initio according to the muffin-tin approximation. Each $\gamma^{(\mathrm{n})}$ is convoluted with an appropriate $n$-body distribution function refined during the fitting procedure.

The fit of the EXAFS data has been performed as previously described [7], based only on three two-body signals $\left(\gamma^{(2)}\right)$. The amplitude reduction factor $\mathrm{S}_{0}{ }^{2}$ is fixed to 0.75 as determined from crystalline references [7]. The parameters for energy resolution and for correction of electron scattering length are fixed to $1.8 \mathrm{eV}$, which is the intrinsic resolution of the monochromator at $18 \mathrm{keV}$, and at 0 , respectively. The fit is performed on the energy range $18055-19150 \mathrm{eV}$. The parameters used in the fits are for each shell the coordination number $(\mathrm{CN})$, the bond length $(\mathrm{R})$ and the variance (Debye-Waller, $\sigma^{2}$ ).

\section{Results}

\subsection{DSC investigations}

Fig. 1 shows the DSC curves obtained during heating for the different glasses with and without $\mathrm{ZrO}_{2}$. We observe the typical effects of the nucleating role of $\mathrm{ZrO}_{2}$ : the addition of $\mathrm{ZrO}_{2}$ yields the appearance of a new endothermic peak above the glass transition temperature, $\mathrm{T}_{\mathrm{g}}$, for MAS, CAS and LAS glasses. There is also a systematic decrease of several tenths of degrees for all thermodynamic events and especially the first crystallization peak (Table 1).

For ZAS-Zr sample, the first exothermic event appears at lower temperature than for ZAS with a significant increase of the area. The attribution of the different thermodynamic events is beyond the scope of this paper and would require extended X-ray diffraction investigation. For MAS-Zr, the nucleation of $\mathrm{ZrO}_{2}$ (peak at $\sim 954{ }^{\circ} \mathrm{C}$ ) is more separated than that of the glassy matrix (peak at $\sim 1022^{\circ} \mathrm{C}$ ). For CAS-Zr, the exothermic event appearing at low temperature may be assigned to the crystallization of $\mathrm{ZrO}_{2}$ [40]. This again indicates that $\mathrm{ZrO}_{2}$ is active in the crystallization of these glasses, though its influence on the crystallization of the overall glassy matrix is more limited compared with ZAS and MAS systems. The effect of adding $\mathrm{ZrO}_{2}$ is particularly spectacular for the LAS system. Indeed, LAS does not crystallize under the experimental conditions applied in this thermal analysis, whereas an intense exotherm event is seen for LAS-Zr at $837^{\circ} \mathrm{C}$, which is also the thermal event at the lowest temperature observed in this study. Finally, NAS and NAS-Zr glasses do not show any 
thermal event, indicating that, only for this system (and under the present experimental conditions of the thermal analysis), $\mathrm{ZrO}_{2}$ does not have any detectable nucleating role.

\subsection{XANES results}

The $\mathrm{Zr} \mathrm{L} 2,3$-edge XANES spectra (Fig. 2) of ${ }^{[6]} \mathrm{Zr}$, ${ }^{[7]} \mathrm{Zr}$ and ${ }^{[8]} \mathrm{Zr}$ model compounds show the influence of the $\mathrm{Zr}$ coordination number and site geometry. The $\mathrm{L}_{2,3}$ edges are due to transition from $2 \mathrm{p}$ to $4 \mathrm{~d}$ states. In $\mathrm{O}_{\mathrm{h}}$ symmetry, the two peaks in the $\mathrm{Zr} \mathrm{\textrm {L } _ { 3 }}$ - (A1-A2) and $\mathrm{L}_{2^{-}}$ edge spectra (B1-B2) are associated with the crystal field splitting of the $4 \mathrm{~d}_{\text {states into }} \mathrm{t}_{2} \mathrm{~g}$ and eg empty states. The apparent crystal field splitting value is $\Delta_{\text {apparent }}=3.0 \pm 0.5 \mathrm{eV}$ for ${ }^{[6]} \mathrm{Zr}$ model compounds, except for $\mathrm{TiZrO}_{4}\left(\Delta_{\text {apparent }}=2.5 \pm 0.5 \mathrm{eV}\right)$ which exhibits a broadening of $\mathrm{L}_{2,3}$-edges. This arises from an important site distortion that further splits the $\mathrm{t}_{2 \mathrm{~g}}$ and $\mathrm{e}_{\mathrm{g}}$. An even smaller apparent crystal field splitting value, $\Delta_{\text {apparent }}=2.1 \pm 0.5 \mathrm{eV}$, and further broadening and splitting of the final states limit the resolution of edge components in the local site symmetry of the ${ }^{[7]} \mathrm{Zr}$ and ${ }^{[8]} \mathrm{Zr}$ model compounds. These values are consistent with multiplet calculations [41].

The $\mathrm{Zr} \mathrm{L} \mathrm{L}_{2,3}$-edge XANES spectra of the glasses (Fig. 3) can be separated into two groups, LAS-NAS-Zr and (M,Z)AS-CAS-Zr. The former exhibit two well-resolved features with an apparent crystal field splitting value, $\Delta_{\text {apparent }}=2.9 \pm 0.5 \mathrm{eV}$, close to that for regular ${ }^{[6]} \mathrm{Zr}$ model compounds. K-edge XANES spectra (Fig. 4) are also similar for these two glasses with the $\mathrm{C}$ component being more intense than the $\mathrm{B}$ component and similar to those observed in ${ }^{[6]} \mathrm{Zr}$ model compounds [41-43]. The LAS-Zr glass exhibits a first EXAFS oscillation (peak D in Fig. 4) slightly shifted towards high energies compared to the NAS-Zr glass, which suggests a slight difference in the $\mathrm{Zr}$ environment between the two glasses. The preedge feature (labeled "A" in Fig. 4) corresponds to a $1 \mathrm{~s} \rightarrow 4 \mathrm{~d}$ transition, allowed by $\mathrm{p}-\mathrm{d}$ mixing [44]. Its absence in LAS-Zr and NAS-Zr is indicative of a regular ${ }^{[6]} \mathrm{Zr}$ site, as observed in crystalline zirconosilicates [7,19,43,44].

For (M,Z)AS,CAS-Zr glasses, the apparent crystal field splitting value derived from $\mathrm{Zr}$ $\mathrm{L}_{2,3}$-edge XANES spectra (Fig. 3) decreases to $2.0 \pm 0.5 \mathrm{eV}$, without significant broadening of the edge features. These values are close to those found for ${ }^{[7]} \mathrm{Zr}$ and ${ }^{[8]} \mathrm{Zr}$ model compounds. K-edge XANES spectra (Fig. 4) are all similar for the $\mathrm{Mg}, \mathrm{Ca}$ and $\mathrm{Zn}$ aluminosilicate glasses with $\mathrm{B}$ and $\mathrm{C}$ components of equivalent intensity. Moreover, a pre-edge $\mathrm{A}$ is always observed, indicating the presence of $\mathrm{Zr}$ sites distorted from centrosymmetry. As in MAS- $\mathrm{Zr}$ [19], $\mathrm{Zr}$ is 
present in a high coordinated site in $\mathrm{Mg}, \mathrm{Ca}, \mathrm{Zn}$-bearing aluminosilicate glasses. Despite minor differences in the $\mathrm{K}$ and $\mathrm{L}_{2,3}$-edge XANES spectra, the $\mathrm{Zr}$ environment in CAS-Zr is close to that in $(\mathrm{M}, \mathrm{Z}) \mathrm{AS}-\mathrm{Zr}$ glasses.

\subsection{EXAFS results}

The Zr K-edge EXAFS spectra (Fig. 5a) of the investigated glasses are very contrasted: for LAS-Zr and NAS-Zr, there is a single, dominant contribution, as the spectra obtained for CAS-Zr, MAS-Zr, ZMAS-Zr and ZAS-Zr are more complex and less intense, indicating the contribution from various neighboring shells. This is well illustrated by the moduli of the Fourier transforms, which are five times more intense in the former, due to the contribution of the oxygen coordination shell (Fig. 5b), as the latter shows a more important contribution from the second and third next-nearest neighbors relative to the oxygen shell.

The $\mathrm{Zr}$ environment for the ZMAS-Zr glass has been previously described [7]: it corresponds to a first shell of 7 oxygen neighbors at $2.11 \AA$, a second shell of ( $\mathrm{Si}, \mathrm{Al}, \mathrm{Mg}$ ) atoms at $3.11 \AA$ and a $\mathrm{Zr}$ shell at $3.38 \AA$. This environment is similar for ZAS-Zr, MAS-Zr and CAS-Zr (Fig. 5, Table 2). The local structure around $\mathrm{Zr}$ for these glasses may then be described by the presence of edge-sharing ${ }^{[7]} \mathrm{Zr}$ sites (Fig. 6a).

The NAS-Zr glass shows the presence of ${ }^{[6]} \mathrm{Zr}$, in accordance with XANES results. A similar coordination has been found in alkali (boro)silicate glasses [41]. This contribution dominates the EXAFS spectrum. A second shell involves $\mathrm{Si}$ and/or Al neighbors. The $\mathrm{Zr}-$ $(\mathrm{Si}, \mathrm{Al})$ distances are larger than in the other glasses investigated, indicating corner-sharing linkages. On the contrary, in the glasses based on divalent cations and the LAS-Zr glass, $\mathrm{Zr}$ polyhedron mainly shares edge linkages with other ( $\mathrm{Si}, \mathrm{Al}$ ) polyhedra (see below). Including a further $\mathrm{Zr}$ shell improves only slightly the fit: this is consistent with the absence of $\mathrm{Zr}-\mathrm{Zr}$ correlations in $\mathrm{Na}$ silicate and aluminoborosilicate glasses [21,41,42].

In LAS-Zr, EXAFS data indicate the presence of ${ }^{[6]} \mathrm{Zr}$ environment, as in NAS-Zr and in accordance with $\mathrm{L}_{2,3}$ and $\mathrm{K}$-edge XANES data. Here too, this contribution dominates the EXAFS spectrum. The average $\mathrm{Zr}-\mathrm{O}$ distance is smaller for ${ }^{[6]} \mathrm{Zr}$ than for ${ }^{[7]} \mathrm{Zr}$. As in NAS-Zr, the variance of the $\mathrm{Zr}-\mathrm{O}$ distances is lower than for $(\mathrm{Z}, \mathrm{M}, \mathrm{C}) \mathrm{AS}-\mathrm{Zr}$, an indication of a lower $\mathrm{Zr}$ coordination number and a less distorted site, which is also confirmed by the lack of a preedge feature $A$ in the K-edge XANES spectrum (Fig. 4) and the symmetric shape of the $L_{2,3}$ XANES spectrum. However, the Debye-Waller like parameter is twice larger than in NAS, indicating some radial disorder. A major difference with NAS-Zr is the presence of ( $\mathrm{Si}, \mathrm{Al})$ 
neighbors at $3.07 \AA$. This short distance indicates edge-sharing linkages, similar to observations for the glasses containing divalent cations, and opposed to the corner-sharing linkage observed in NAS-Zr.

\section{Discussion}

\subsection{Zr-coordination number}

An important result of our investigation is that $\mathrm{Zr}$ coordination cannot be a relevant parameter to establish the nucleating role of this element. Indeed, $\mathrm{Zr}$ in octahedral sites can be observed in the LAS glass where $\mathrm{ZrO}_{2}$ is a strong, widely used, nucleating agent and in the NAS glass, where no nucleation occurs in the experimental condition of our DSC measurements. This suggests that structural differences between these glasses may occur in the medium range order.

The nucleating effect of $\mathrm{ZrO}_{2}$ in ZAS, MAS, CAS and LAS glasses is accompanied by a decrease in the crystallization temperatures (Fig. 1, Table 1). The LAS system shows the greatest influence of $\mathrm{ZrO}_{2}$ as a nucleating agent: no crystallization is observed for LAS while LAS-Zr exhibits the lowest temperature exotherm for all aluminosilicate glasses. This result explains, in part, the attractiveness of this system in industrial applications. The only sample for which the introduction of $\mathrm{ZrO}_{2}$ has no influence, given the chosen experimental conditions of thermal analysis, is NAS-Zr. The structure of this glass and the environment around $\mathrm{Zr}$ is thus a paramount issue to understand the role of nucleating agent of $\mathrm{ZrO}_{2}$.

XANES results indicate that $\mathrm{Zr}$ coordination depends on the nature of the cation: ${ }^{6{ }^{6} \mathrm{Zr}}$ with alkalis and ${ }^{[7]} \mathrm{Zr}$ with divalent cations. In alkali aluminosilicate glasses, $\mathrm{Zr}$ environment corresponds to ${ }^{\left[{ }^{6}\right]} \mathrm{Zr}$ sites, as observed for silicate and borosilicate glasses [21,41]. In (Z,M,C)AS-Zr glasses, the interpretation is less straightforward. The $\mathrm{L}_{2,3}$-edges spectra for these glasses share some similarities with the spectrum for $\mathrm{ZrTiO}_{4}$. In this crystalline reference, $\mathrm{Zr}$ is in a strongly distorted octahedral site with distances at 1.766, 2.051 and $2.296 \AA$ [27]. However, the apparent crystal field splitting values for the glasses are significantly lower $(2.0 \mathrm{eV})$ than that for $\mathrm{ZrTiO}_{4}(2.5 \mathrm{eV})$, whereas they are very close to those for crystalline references containing ${ }^{[7]} \mathrm{Zr}(2.1 \mathrm{eV})$. Moreover, a previous EXAFS investigation of MAS-Zr glass has evidenced a $\mathrm{Zr}-\mathrm{O}$ coordination number close to 7 with an average $\mathrm{Zr}-\mathrm{O}$ distance at $2.11 \AA$ [7]. Therefore, rather than a distorted ${ }^{[6]} \mathrm{Zr}$ site, we expect that $\mathrm{Zr}$ is localized in ${ }^{[7]} \mathrm{Zr}$ sites in $(\mathrm{Z}, \mathrm{M}, \mathrm{C}) \mathrm{AS}-\mathrm{Zr}$ glasses, given the similarities between all 
spectra.

For the CAS-Zr glass, the results differ from a previous EXAFS investigation of a calcium silicate glass containing $\mathrm{Zr}[17,45]$, in which it was concluded to an octahedral $\mathrm{Zr}$ environment (with $\mathrm{CN}=5.5-6.8$ ) with a $\mathrm{Zr}-\mathrm{O}$ distance of 2.08-2.14 $\AA$. The XANES spectra for CAS-Zr (Fig. 3 and Fig. 4) are slightly different from those of (Z,M)AS-Zr glasses, which could indicate the presence of lower coordinated $\mathrm{Zr}$ sites for CAS-Zr, but with a small amount. The presence of minority ${ }^{[7]} \mathrm{Zr}$ has been also suggested in borosilicate glasses, with high zirconia content but with no evidence of $\mathrm{Zr}-\mathrm{Zr}$ pair correlations [46]. In highly polymerized natural glasses (rhyolitic compositions), the mean $\mathrm{Zr}-\mathrm{O}$ distance $(2.10 \pm 0.01 \AA$ ) and the appearance of $\mathrm{Zr}-\mathrm{Zr}$ contributions at $\sim 3.67 \pm 0.05 \AA$ were interpreted as evidence for minor amounts of ${ }^{[8]} \mathrm{Zr}$ [47]. In our glasses, the polymerization of the network cannot be the reason for the different $\mathrm{Zr}$ coordination number because all the studied glasses are slightly peraluminous and thus with few non-bridging oxygens. The nature of alkali or alkaline-earth cations impacts the charge compensation of $\mathrm{Zr}$ polyhedra. Similarly to $\mathrm{Zr}, \mathrm{Al}$ is often observed in high coordinated sites when alkaline-earth cations are present $[48,49]$. This corresponds to a less favorable charge compensating role of alkaline-earth cations compared to alkali cations [50].

\subsection{Medium range organization: the linkage to the aluminosilicate network}

The $\mathrm{Zr}$ polyhedra are associated with the aluminosilicate network as show by the (Si,Al) second shell. Al coordination has been investigated in MAS and CAS glasses, with ${ }^{[5]} \mathrm{Al}$ and ${ }^{[6]} \mathrm{Al}$ present even in peralkaline compositions $\left(\mathrm{RO} / \mathrm{Al}_{2} \mathrm{O}_{3}>1\right.$ with $\mathrm{R}=\mathrm{Ca}$ or $\left.\mathrm{Mg}\right)[48,49,51,52]$. However, these highly coordinated Al-species are not observed in alkali aluminosilicate

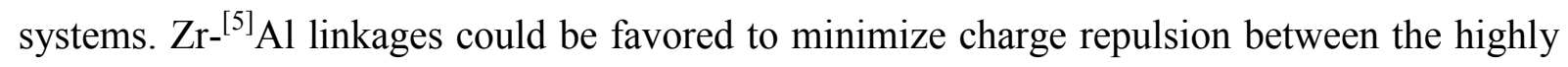
charged cations: the short $\mathrm{Zr}(\mathrm{Si}, \mathrm{Al})$ distance of $3.1 \AA$ (Table 2 ) is similar to the ${ }^{[8]} \mathrm{Zr}-\mathrm{Si}$ bond length of $2.98 \AA$ in crystalline $\mathrm{ZrSiO}_{4}$ corresponding to edge-sharing. This is the $\mathrm{Zr}$ environment proposed in Figure $6 \mathrm{~b}$ for $\mathrm{ZrO}_{7}$ polyhedra in $(\mathrm{Z}, \mathrm{M}, \mathrm{C}) \mathrm{AS}-\mathrm{Zr}$ glasses. In $\mathrm{LAS}-\mathrm{Zr}$, the $\mathrm{Zr}$-(second neighbor) distance is short (3.07 $\AA$, Table 2). This could be due to higher ${ }^{[4]} \mathrm{Al}$ neighbors as ${ }^{[5]} \mathrm{Al}$ content is small in alkali aluminosilicate glasses. A schematic representation of the $\mathrm{Zr}$ environment for this glass is proposed in Figure $6 \mathrm{~b}$ that shows a $\mathrm{ZrO}_{6}$ octahedron sharing edges with another $\mathrm{ZrO}_{6}$ octahedron and $(\mathrm{Si}, \mathrm{Al})$ tetrahedra. On the contrary, in the NAS-Zr glass, the $\mathrm{Zr}(\mathrm{Si}, \mathrm{Al})$ distances are longer (3.42 $\AA$, Table 2$)$ suggesting a more open structure with corner sharing polyhedra (Fig. 6c). 
Edge-sharing distances between cations may explain the limited thermal stability of the investigated glasses containing $\mathrm{Li}, \mathrm{Mg}, \mathrm{Ca}$ or $\mathrm{Zn}$. By contrast, the longer $\mathrm{Zr}-(\mathrm{Al}, \mathrm{Si})$ distance minimizes electrostatic repulsion between cations, which may explain the lower crystallization ability for the NAS-Zr composition.

\subsection{Medium range organization: Zr clustering.}

A major influence on the nucleation processes could be the $\mathrm{Zr}$ distribution within the aluminosilicate network. Indeed, EXAFS signals show strong evidence for direct linkages between $\mathrm{Zr}$ polyhedra for MAS-Zr glasses [7] and direct visualization of heterogeneous $\mathrm{Zr}$ distribution has been observed for MAS and (Z,M)AS glasses [11,53]. Direct linkages between ${ }^{[6]} \mathrm{Zr}$ is uncommon in zirconosilicates: for baghdadite [31], edge-sharing between ${ }^{[6]} \mathrm{Zr}$ polyhedra gives a short $\mathrm{Zr}-\mathrm{Zr}$ distance of $3.25 \AA$ while, in $\mathrm{TiZrO}_{4}$ [27], both edge- and corner-sharing are present giving $\mathrm{Zr}-\mathrm{Zr}$ distances at 3.60 and 3.38-3.55 $\AA$, respectively. These latter values are close to the average $\mathrm{Zr}-\mathrm{Zr}$ distance found in the EXAFS analysis (Table 2).

The presence of $\mathrm{Zr}$ second neighbors is not well established for the NAS-Zr glass, though the possibility of $\mathrm{Zr}$ second neighbors cannot be completely ruled out. A relationship between the role of nucleating agent of $\mathrm{Zr}$ and its distribution within the glassy matrix may be correlated with the EXAFS evidence of $\mathrm{Zr}$ clustering for the (Z,M,C)AS-Zr and LAS-Zr glasses contrary to the NAS-Zr glass (Table 2). The close proximity between the Zr cations favors the apparition of $\mathrm{ZrO}_{2}$ nano-crystals upon heat treatment. These crystals are the first to appear in these aluminosilicate glasses prior to the formation of different phases resulting from the crystallization of the aluminosilicate network [11]. As intersite linkages are made through edge-sharing in both the starting glass and the nucleated crystals, a medium-range ordering around $\mathrm{Zr}$ polyhedra will require small rearrangements and small atomic displacement to form crystallites.

There is thus a relationship between the role of nucleating agent of $\mathrm{Zr}$ and its distribution within the glassy matrix. The proposed trend of $\mathrm{Zr}$ clustering for the (Z,M,C)AS$\mathrm{Zr}$ glasses can be extended to LAS-Zr glass and an homogeneous $\mathrm{Zr}$ distribution in NAS- $\mathrm{Zr}$ glass could be a reason explaining the different crystallization behavior.

The importance for the nucleation processes of the medium range organization of the initial glass has already been observed in the case of $\mathrm{TiO}_{2}$ where preferential linkages between $\mathrm{Ti}$ and $\mathrm{Al}$ polyhedra mimics the first nano-crystals formed upon heat treatments $[8,12,13]$. Highly coordinated Al species play an important role in the formation of structural 
fluctuations in the system. Indeed Al is usually found in six-fold coordinated sites in crystals and the pre-existence of high coordinated $\mathrm{Al}$ in the glass lowers diffusion processes and energy barriers associated to a coordination change from $\mathrm{AlO}_{4}$ to $\mathrm{AlO}_{6}$.

\section{Conclusion}

We report a study on the environment of $\mathrm{Zr}$ in aluminosilicate glasses using $\mathrm{Zr} \mathrm{K}$ - and $\mathrm{L}_{2,3}$ edges X-ray absorption spectroscopy, in relation with its nucleating agent properties. Differential Scanning Calorimetry measurements have shown a strong nucleating role for $\mathrm{Zr}$ in Li-bearing aluminosilicate glasses and in $\mathrm{Mg}$-, $\mathrm{Ca}$ - and $\mathrm{Zn}$-bearing aluminosilicate glasses. On the contrary, adding $\mathrm{ZrO}_{2}$ in sodium aluminosilicate glasses does not induce any crystallization. We have shown that the local order is not responsible for this nucleating role. Indeed, six-fold coordinated site has been determined for both Li- and Na-bearing glasses. In Mg-, Ca- and Zn-bearing glasses, a different $\mathrm{Zr}$ local environment has been found with sevenfold coordination. These results suggest that the origin of the nucleating role must be found at medium range order, in relation with the $\mathrm{Zr}$ distribution within the aluminosilicate network.

\section{Acknowledgments}

Authors wish to acknowledge Pierre Lagarde (SOLEIL), Anne-Marie Flank (SOLEIL) for help in data acquisition and SOLEIL for provision of synchrotron radiation facilities (proposal ID 20090264). DSC thermograms were performed at Saint-Gobain Recherche with the valuable help from Samuel Pierre.

\section{References}

[1] G.H. Beall, L.R. Pinckney, J. Am. Ceram. Soc. 82 (1999) 5-16.

[2] G.H. Beall, J. Eur. Ceram. Soc. 29 (2009) 1211-1219.

[3] H.R. Fernandes, D.U. Tulyaganov, J.M.F. Ferreira, J. Mater. Sci. 48 (2013) 765-773.

[4] T.I. Barry, J.M. Cox, R. Morrell, J. Mater. Sci. 13 (1978) 594-610.

[5] R.D. Maurer, J. Appl. Phys. 33 (1962) 2132-2139.

[6] G.F. Neilson, J. Appl. Phys. 43 (1972) 3728-3735.

[7] O. Dargaud, L. Cormier, N. Menguy, L. Galoisy, G. Calas, S. Papin, G. Querel, L. Olivi, Journal of Non-Crystalline Solids 356 (2010) 2928-2934.

[8] M. Guignard, L. Cormier, V. Montouillout, N. Menguy, D. Massiot, J. Non Cryst. Solids 356 (2010) 1368-1373.

[9] S. Sen, T. Mukerji, Journal of Non-Crystalline Solids 246 (1999) 229-239.

[10] E.D. Zanotto, V.M. Fokin, Phil. Trans. R. Soc. Lond. A 361 (2003) 591-613. 
[11] O. Dargaud, L. Cormier, N. Menguy, G. Patriarche, G. Calas, Appl. Phys. Lett. 99 (2011) 021904.

[12] M. Guignard, L. Cormier, V. Montouillout, N. Menguy, D. Massiot, A.C. Hannon, J. Phys.: Condens. Matter 21 (2009) 375107.

[13] M. Guignard, L. Cormier, V. Montouillout, N. Menguy, D. Massiot, A.C. Hannon, B. Beuneu, J. Phys.: Condens. Matter 22 (2010) 185401.

[14] T. Dumas, A. Ramos, M. Gandais, J. Petiau, J. Mater. Sci. Lett. 4 (1985) 129-132.

[15] A. Ramos, M. Gandais, J. Petiau, J. Phys. C8-Suppl N¹2, tome 46 (1985) C8-491-C498494.

[16] G.N. Greaves, W. Bras, M. Oversluizen, S.M. Clarck, Faraday Discuss. 122 (2002) 299314.

[17] C. Meneghini, S. Mobilio, L. Lusvarghi, F. Bondioli, A.M. Ferrari, T. Manfredini, C. Siligardi, J. Appl. Cryst. 37 (2004) 890-900.

[18] T. Dumas, J. Petiau, Journal of Non-Crystalline Solids 81 (1986) 201-220.

[19] O. Dargaud, G. Calas, L. Cormier, L. Galoisy, C. Jousseaume, G. Querel, M. Newville, J. Am. Ceram. Soc. 93 (2010) 342-344.

[20] L. Cormier, O. Dargaud, N. Menguy, G.H. Henderson, M. Guignard, N. Trcera, B.

Watts, Cryst. Growth Des. 11 (2011) 311-319.

[21] G. Ferlat, L. Cormier, M.H. Thibault, L. Galoisy, G. Calas, J.M. Delaye, D. Ghaleb, Phys. Rev. B 73 (2006) 214207.

[22] E. Apel, C. van't Hoen, V. Rheinberger, W. Höland, J. Eur. Ceram. Soc. 27 (2007) 15711577.

[23] W. Zdaniewski, J. Am. Ceram. Soc. 58 (1975) 163-169.

[24] E. Pélegrin, G. Calas, P. Ildefonse, P. Jollivet, L. Galoisy, Journal of Non-Crystalline Solids 356 (2010) 2497-2508.

[25] O. Spalla, P. Barboux, L. Sicard, S. Lyonnard, F. Bley, Journal of Non-Crystalline Solids 347 (2004) 56-68.

[26] G. Calas, L. Cormier, L. Galoisy, P. Jollivet, C. R. Chimie 5 (2002) 831-843.

[27] P. Bordet, A. McHale, A. Santoro, R.S. Roth, J. Solid State Chem. 64 (1986) 30-46.

[28] E. Cannillo, G. Rossi, L. Ungarett, Am. Mineral. 58 (1973) 106-109.

[29] Y. Le Page, G. Perrault, Can. Mineral. 14 (1976) 132-138.

[30] A. Sidike, I. Kusachi, N. Yamashita, Phys. Chem. Mineral. 32 (2006) 665-669.

[31] J.R. Plaisier, J. Jansen, R.A.G. de Graaff, D.J.W. Ijdo, J. Solid State Chem. 115 (1995) 464-468.

[32] D.K. Smith, H.W. Newkirk, Acta Cryst. 18 (1965) 983.

[33] C.J. Howard, R.J. Hill, B.E. Reichert, Acta Cryst. B 44 (1988) 116-120.

[34] R.M. Hazen, L.W. Finger, Am. Mineral. 64 (1979) 196-201.

[35] G. Della Gatta, M.J. Richardson, S.M. Sarge, S. Stolen, Pure and Applied Chemistry 78 (2006) 1455-1476.

[36] A.M. Flank, G. Cauchon, P. Lagarde, S. Bac, M. Janousch, R. Wetter, J.M. Dubuisson, M. Idir, F. Langlois, T. Moreno, D. Vantelon, Nucl. Instr. Meth. Phys. Res. B 246 (2006) 269-274.

[37] B. Ravel, M. Newville, J. Synchrotron Rad. 12 (2005) 537-541.

[38] A. Di Cicco, G. Aquilanti, M. Minicucci, E. Principi, N. Novello, A. Cognigni, L. Olivi, J. Phys.: Conf. Series 190 (2009) 012043.

[39] A. Filipponi, A. Di Cicco, Phys. Rev. B 52 (1995) 15135-15149.

[40] E. Strukejl, Propriétés et cristallisation des liquides aluminosilicatés : influence du titane et du zirconium, Universté Pierre et Marie Curie, Paris, 2010.

[41] L. Galoisy, E. Pellegrin, M.-A. Arrio, P. Ildefonse, G. Calas, J. Am. Ceram. Soc. 82 (1999) 2219-2224. 
[42] F. Farges, C.W. Ponader, G.E. Brown Jr., Geochim. Cosmochim. Acta 55 (1991) 15631574.

[43] F. Farges, S. Rossano, Eur. J. Mineral. 12 (2000) 1093-1107.

[44] P. Li, I.W. Chen, J.E. Pennerhahn, Phys. Rev. B 48 (1993) 10063-10073.

[45] C. Meneghini, A.F. Gualtieri, C. Siligardi, J. Appl. Cryst. 32 (1999) 1090-1099.

[46] D.A. McKeown, I.S. Muller, A.C. Buechele, I.L. Pegg, Journal of Non-Crystalline Solids 258 (1999) 98-109.

[47] F. Farges, Chemical Geology 127 (1996) 253-268.

[48] D.R. Neuville, L. Cormier, V. Montouillout, P. Florian, F. Millot, J.-C. Rifflet, D.

Massiot, Am. Mineral. 93 (2008) 1721-1731.

[49] D.R. Neuville, L. Cormier, V. Montouillout, D. Massiot, Journal of Non-Crystalline Solids 353 (2007) 180-184.

[50] F. Angeli, T. Charpentier, D. de Ligny, C. Cailleteauz, J. Am. Ceram. Soc. 93 (2010) 2693-2704.

[51] D.R. Neuville, L. Cormier, D. Massiot, Geochim. Cosmochim. Acta 68 (2004) 50715079 .

[52] D.R. Neuville, L. Cormier, D. Massiot, Chemical Geology 229 (2006) 173-185.

[53] O. Dargaud, L. Cormier, N. Menguy, G. Patriarche, Journal of Non-Crystalline Solids 358 (2012) 1257-1262. 


\section{Table 1}

Nominal composition (mol\%) of the glasses investigated in this study. Temperature of the first crystallization peak $\left(T_{C}\right)$ with a precision $\pm 0.5^{\circ} \mathrm{C}$.

$\begin{array}{llllllllll}\text { Glass } & \mathrm{ZnO} & \mathrm{MgO} & \mathrm{CaO} & \mathrm{Li}_{2} \mathrm{O} & \mathrm{Na}_{2} \mathrm{O} & \mathrm{Al}_{2} \mathrm{O}_{3} & \mathrm{SiO}_{2} & \mathrm{ZrO}_{2} & \mathrm{~T}_{\mathrm{C}}\left({ }^{\circ} \mathrm{C}\right) \\ \text { ZAS } & 11.08 & & & & & 13.45 & 75.47 & & 940.9 \\ \text { ZAS-Zr } & 10.64 & & & & & 12.91 & 72.42 & 4.03 & 918.2 \\ \text { ZMAS- } & 2.97 & 7.67 & & & & 12.91 & 72.42 & 4.03 & 947.8 \\ \mathrm{Zr} & & & & & & & & & \\ \text { MAS } & & 11.08 & & & & 13.45 & 75.47 & & 1032.4 \\ \text { MAS-Zr } & 10.64 & & & & 12.91 & 72.42 & 4.03 & 954.0 \\ \text { CAS } & & & 11.08 & & & 13.45 & 75.47 & & 1258.3 \\ \text { CAS-Zr } & & & 10.64 & & & 12.91 & 72.42 & 4.03 & 971.4 \\ \text { LAS } & & & 11.08 & & 13.45 & 75.47 & & - \\ \text { LAS-Zr } & & & 10.64 & & 12.91 & 72.42 & 4.03 & 837.2 \\ \text { NAS } & & & & 11.08 & 13.45 & 75.47 & & - \\ \text { NAS-Zr } & & & & 10.64 & 12.91 & 72.42 & 4.03 & -\end{array}$




\section{Table 2}

Fitting parameters for the different glasses: coordination number $(\mathrm{N})$, distance, $\mathrm{R}$, and standard deviation $(\sigma)$.

$\begin{array}{llll}\text { Zr-O shell } & \mathrm{N} & \mathrm{R}(\AA) & \sigma\left(\AA^{2}\right) \\ \text { MAS-Zr } & 7.2 \pm 0.3 & 2.11 \pm 0.01 & 0.019 \pm 0.002 \\ \text { ZAS-Zr } & 7.2 \pm 0.8 & 2.12 \pm 0.01 & 0.018 \pm 0.002 \\ \text { CAS-Zr } & 7.1 \pm 0.4 & 2.10 \pm 0.01 & 0.018 \pm 0.002 \\ \text { LAS-Zr } & 6.0 \pm 0.1 & 2.09 \pm 0.01 & 0.004 \pm 0.002 \\ \text { NAS-Zr } & 6.1 \pm 0.1 & 2.08 \pm 0.01 & 0.002 \pm 0.002 \\ \text { Zr-(Si,Al) shell } & \mathrm{N} & \mathrm{R}(\AA) & \sigma\left(\AA^{2}\right) \\ \text { MAS-Zr } & 3.1 \pm 0.5 & 3.12 \pm 0.02 & 0.024 \pm 0.003 \\ \text { ZAS-Zr } & 2.8 \pm 1.7 & 3.11 \pm 0.02 & 0.021 \pm 0.003 \\ \text { CAS-Zr } & 3.1 \pm 1.4 & 3.11 \pm 0.02 & 0.032 \pm 0.003 \\ \text { LAS-Zr } & 1.1 \pm 0.7 & 3.07 \pm 0.03 & 0.014 \pm 0.008 \\ \text { NAS-Zr } & 1.0 \pm 0.5 & 3.42 \pm 0.02 & 0.001 \pm 0.003 \\ \text { Zr-Zr shell } & \mathrm{N} & \mathrm{R}(\AA) & \sigma\left(\AA^{2}\right) \\ \text { MAS-Zr } & 0.8 \pm 0.3 & 3.38 \pm 0.03 & 0.005 \pm 0.004 \\ \text { ZAS-Zr } & 0.7 \pm 0.3 & 3.38 \pm 0.03 & 0.004 \pm 0.004 \\ \text { CAS-Zr } & 1.2 \pm 0.3 & 3.38 \pm 0.03 & 0.008 \pm 0.004 \\ \text { LAS-Zr } & 0.9 \pm 0.3 & 3.42 \pm 0.03 & 0.006 \pm 0.004\end{array}$




\section{Figure Captions}

Fig. 1. Differential scanning calorimetry curves of the glasses without (orange) and with (blue) $\mathrm{ZrO}_{2}$. From top to bottom, (a) MAS and MAS-Zr, (b) ZAS and ZAS-Zr, (c) CAS and CAS-Zr, (d) LAS and LAS-Zr, (e) NAS and NAS-Zr. Some curves have been shifted for clarity.

Fig. 2. (a) $\mathrm{Zr} \mathrm{L} \mathrm{L}_{2}$-edge and (b) $\mathrm{L}_{3}$-edge spectra for crystalline references with different $\mathrm{Zr}$ environment.

Fig. 3. (a) $\mathrm{Zr} \mathrm{L} \mathrm{L}_{2}$-edge and (b) $\mathrm{L}_{3}$-edge spectra for $\mathrm{Zr}$-bearing glasses. Spectra for LAS-Zr and NAS-Zr (lower curves) are different than those for (MZ)AS-CAS-Zr (upper curves).

Fig. 4. Zr K-edge spectra for Zr-bearing glasses. Spectra for LAS-Zr and NAS-Zr (lower curves) are different than those for (MZ)AS-CAS-Zr (upper curves, shifted by +0.2 for clarity).

Fig. 5. (a) EXAFS signals (plain curves) and theoretical signals (circles). (b) Fourier transforms of the $\mathrm{k}^{2}$-weighted experimental (plain curves) and calculated (circles) EXAFS signals for the different glasses, uncorrected for the phase shift. From top to bottom, (i) NASZr, (ii) LAS-Zr, (iii) CAS-Zr, (iv) MAS-Zr, (v) ZAS-Zr.

Fig. 6. Models based on the extracted EXAFS parameters for (a) the ZAS-Zr, MAS-Zr and CAS-Zr glasses, (b) for the LAS-Zr glass and (c) for the NAS-Zr glass. The (Si,Al) tetrahedra could be occupied also by alkali or akaline-earths and could present different coordination, such as $\mathrm{AlO}_{5}$ or $\mathrm{AlO}_{6}$ polyhedra. 
Figure 1

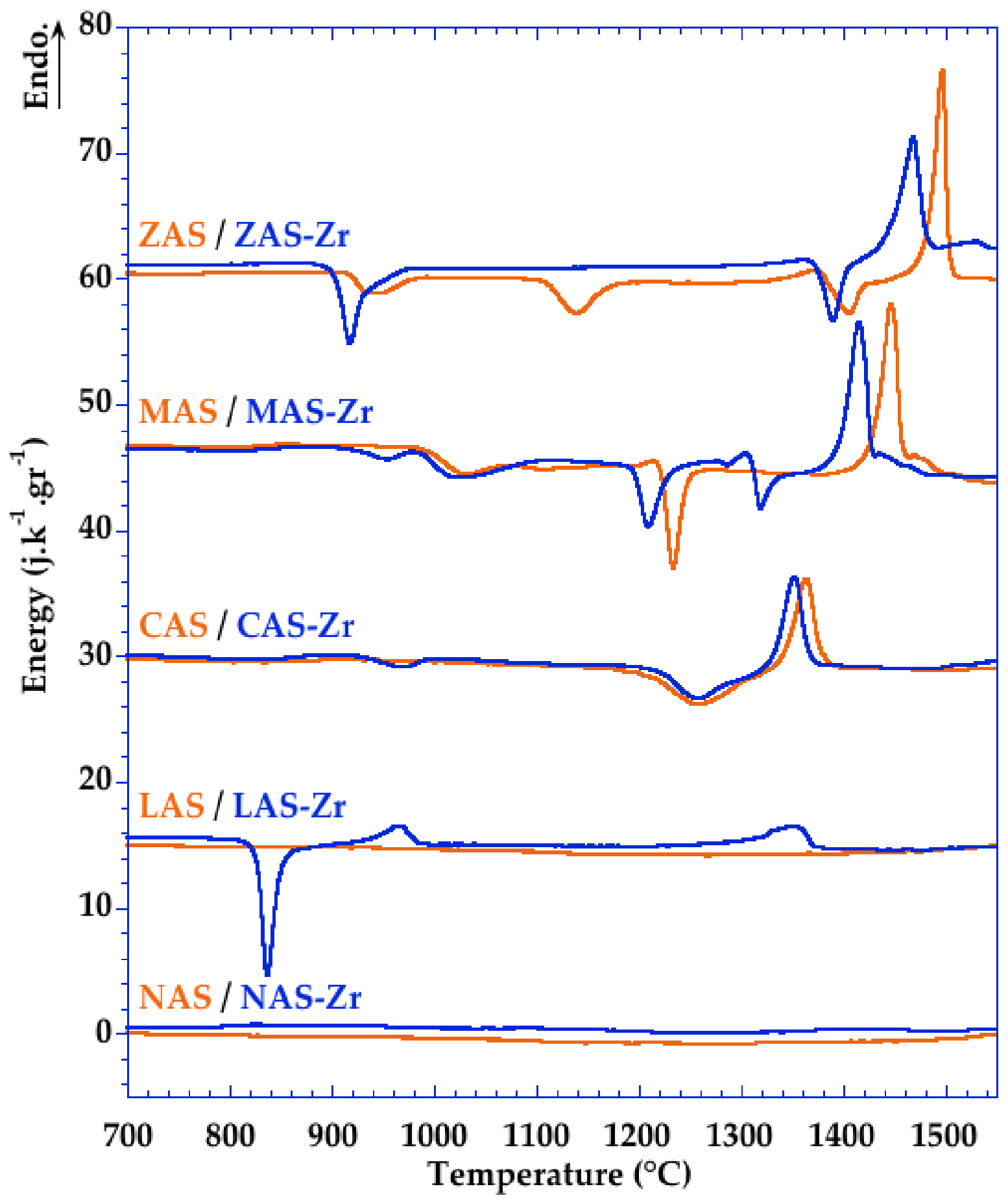


Figure 2
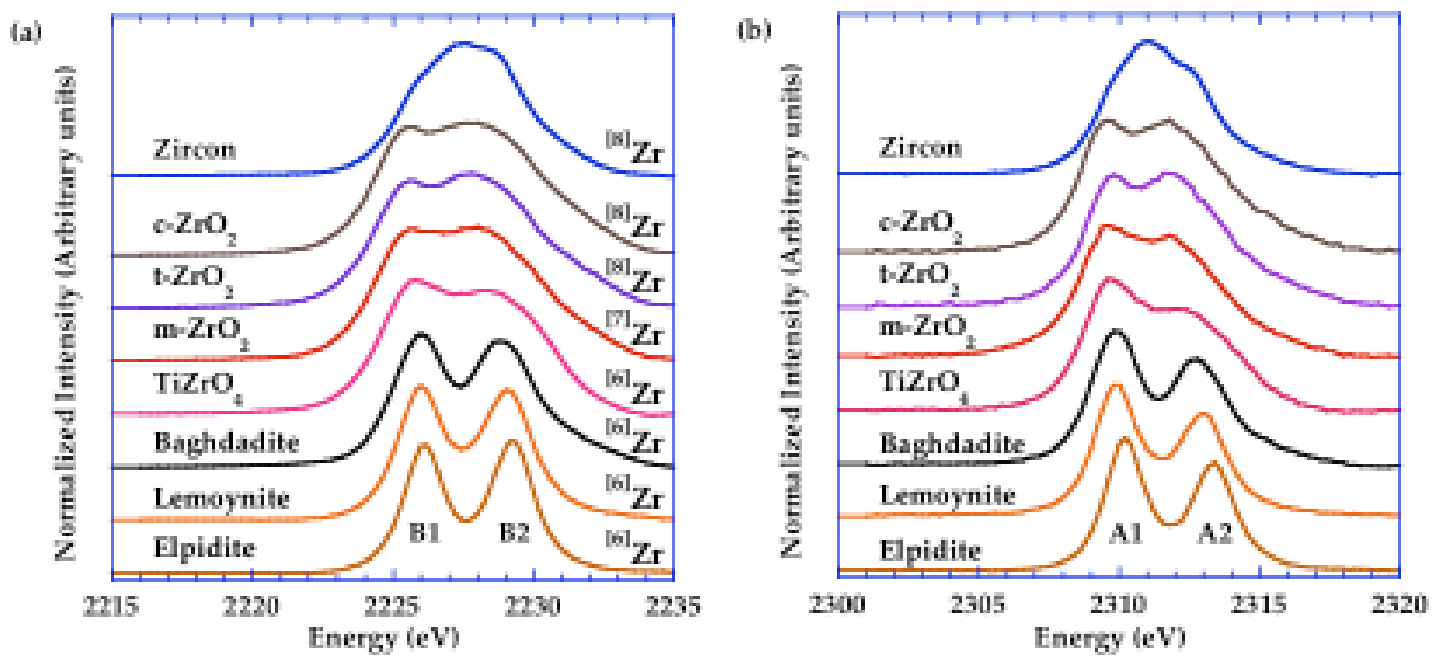
Figure 3
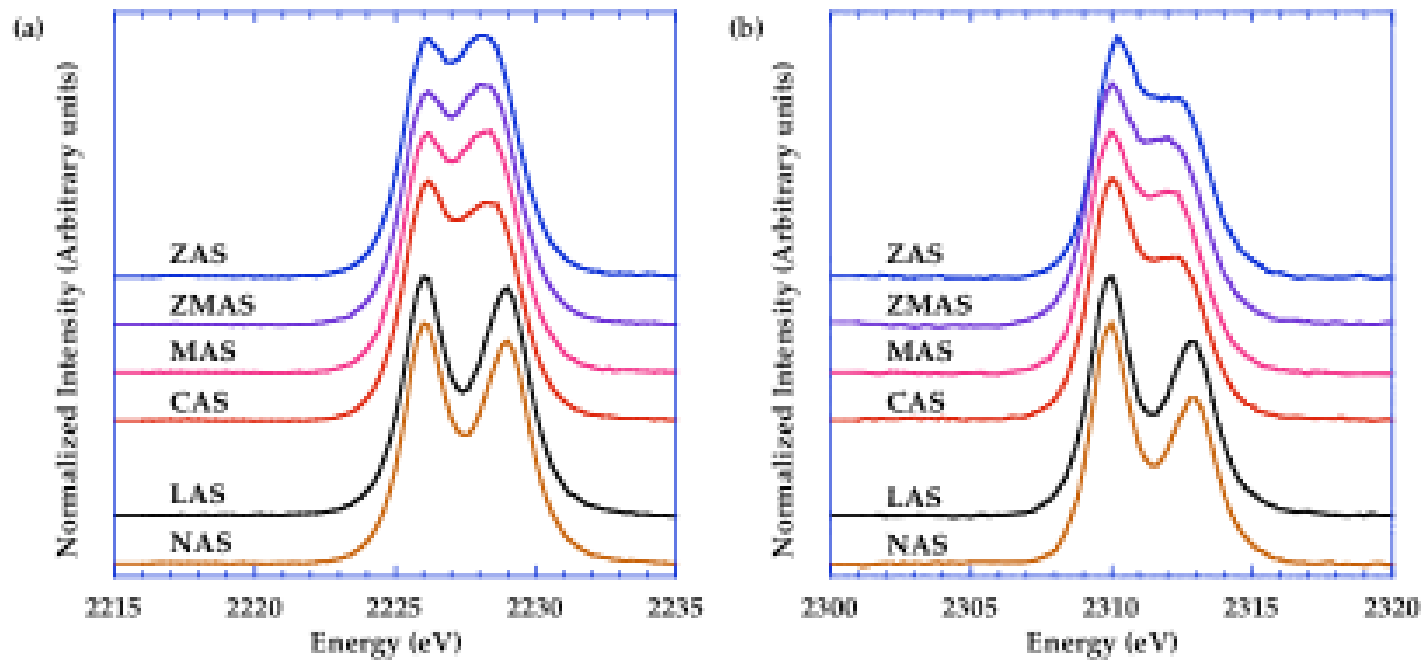
Figure 4

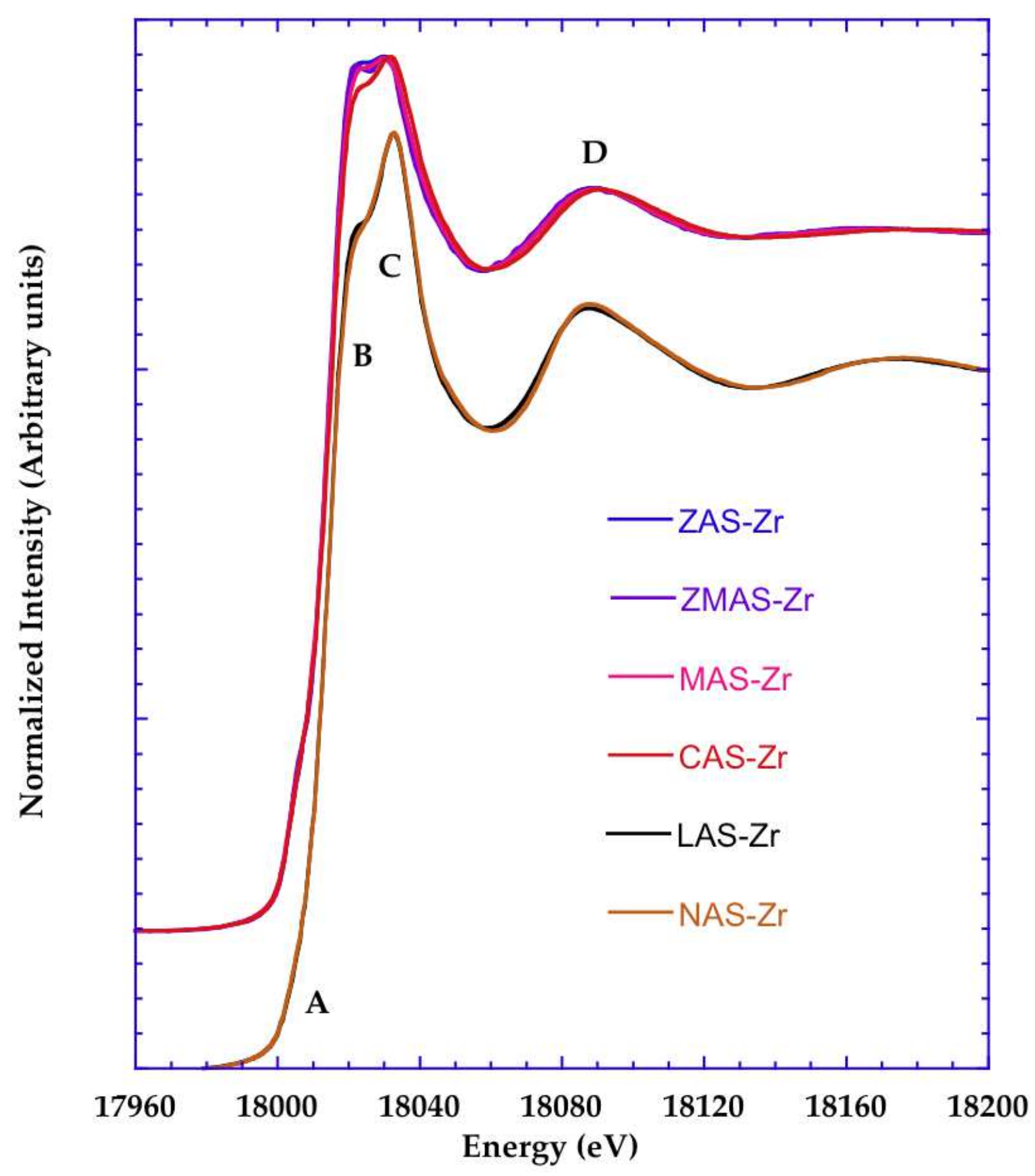


Figure 5

(a)

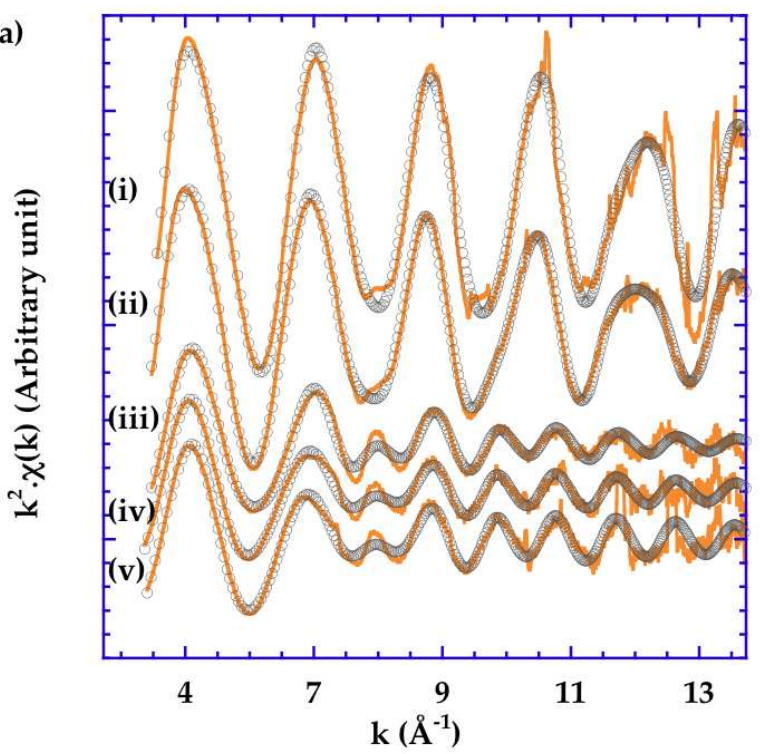

(b)

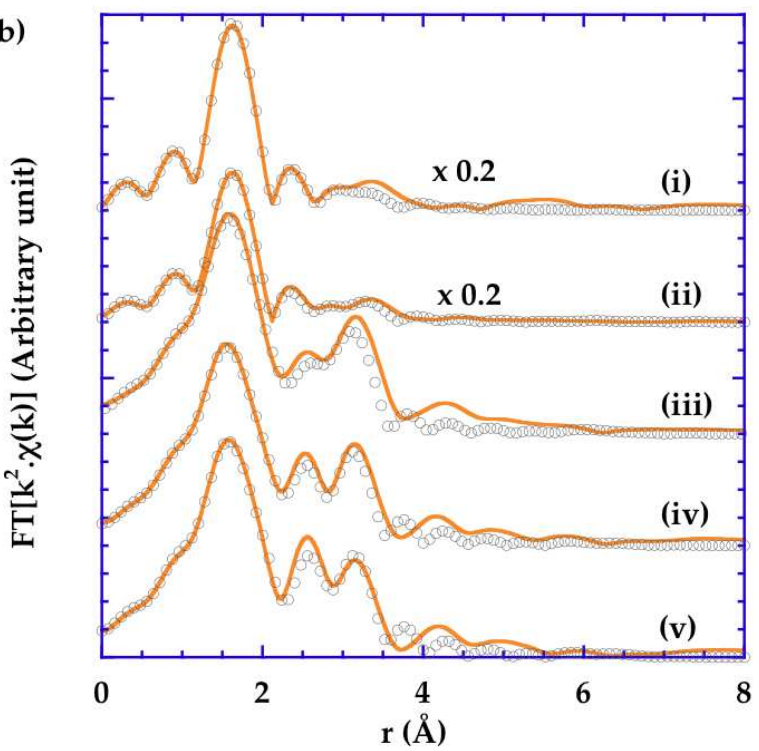


Figure 6

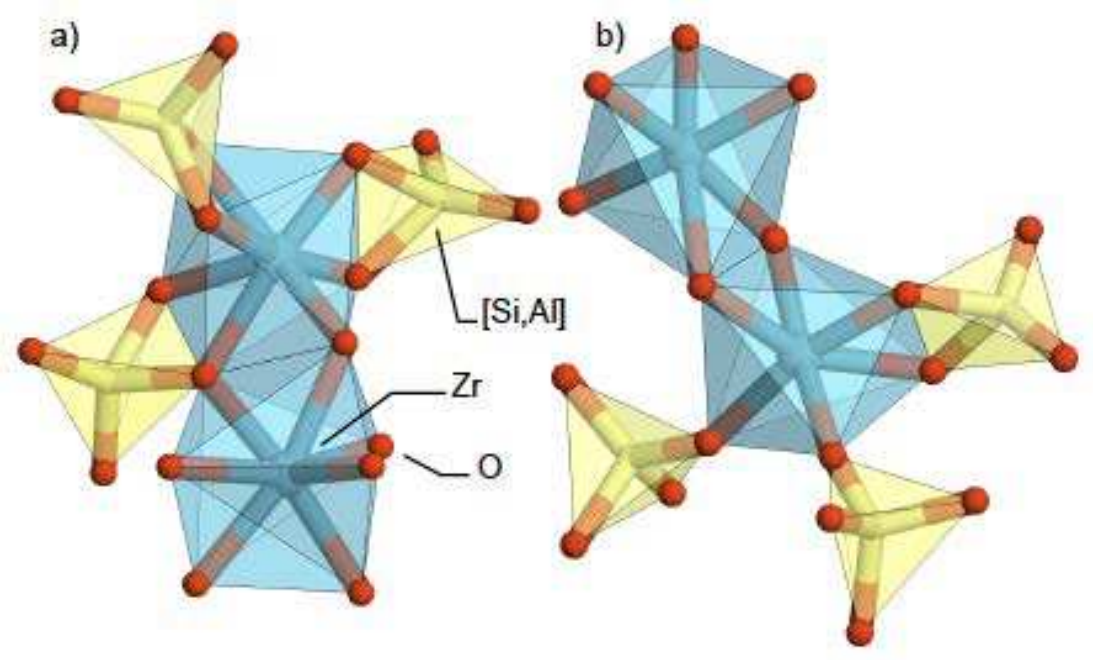

c)

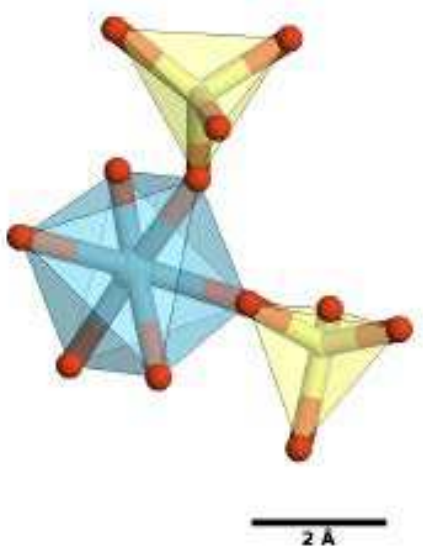

